\title{
SIMULATION OF A DUMMY CRASH TEST IN ADAMS
}

\author{
Marek Jaśkiewicz ${ }^{1, *}$, Damian Frej ${ }^{1}$, Miloš Poliak ${ }^{2}$ \\ ${ }^{1}$ Department of Automotive Engineering and Transport, University of the Kielce University of Technology, Kielce, \\ Poland \\ ${ }^{2}$ Department of Road and Urban Transport, University of Zilina, Zilina, Slovakia \\ *E-mail of corresponding author: m.jaskiewicz@tu.kielce.pl
}

\section{Resume}

The article presents a model designed dummy for crash test in ADAMS. The simulated model dummy has dimensions, shapes and mass corresponding to a 50-percentile man. The simulation program allows modification of the dummy parameters. It allows to study the dynamics of motion, distribution of forces and loads of individual parts of the body of the simulated model. The article describes the design process and how to select the appropriate stiffness and damping joints for the simulated dummy. The article contains the results of simulation crash tests performed in the ADAMS program, which were compared to results of the Hybryd III dummy physical crash test. The simulation is designed to reflect the greatest compliance of the movements of individual parts of the human body during the low speed collision.

\section{Article info}

Received 7 April 2021

Accepted 8 June 2021

Online 5 October 2021

\section{Keywords:}

computer simulation, dummy,

crash test
ISSN 1335-4205 (print version)

ISSN 2585-7878 (online version)

\section{Introduction}

Currently, more attention is paid to safety of people and motor vehicles. Automotive threats are becoming more and more apparent due to increase in the number of vehicles traveling on the roads and capabilities achieved by the high-speed cars [1-3]. The classic division of passenger cars in Europe, as well as in Poland, is based on the size of vehicles There are 10 categories of passenger cars, each category has a different letter of the alphabet. The lower the letter of the alphabet, the lower the vehicle class. Cars from category A and some of B are designed for city driving, which is why one is increasingly seeing versions of these cars with electric motors. On the other hand, category $\mathrm{C}$ and $\mathrm{D}$ cars are designed to cover greater extra-urban distances [2, 4-6]. The intended use of the car plays an important role in terms of safety; usually the city cars have a smaller power unit, which makes them unsuitable for developing high speeds on the road. In contrast, cars designed for longer routes are usually designed to achieve high speeds while driving. The increase in the level of technology favors development of the automotive industry, each car is equipped with several to several dozens of different security systems [6-8].

The issue of choosing the right equipment is more dependent on what the car is intended for. The active safety of a vehicle is affected by its design and equipment, which aims to reduce the risk of a collision or road accident [8-9].
Most car equipment packages include systems such as ABS (Antilock Brake System), ASR (Anti Skid Regulation), ESC (Electronic Stability Control), EBD (Electronic Brake Distributor). There are many other systems that can increase vehicle safety, such as automatic parking systems, Traffic Sign Recognition, side collision threat detection (Side Detect System), rear collision detection (Rear Detect System) or automatic braking vehicle system [1, 8-11].

Each of these systems increases the safety of people in the car and other road users. Before such a system could be introduced to the market, it has to undergo a number of tests and trials, including the crash tests. Tests are usually carried out at a request of the car manufacturers, consumer organizations and insurance companies. Simulation tests of road accidents are conducted worldwide by various institutes and organizations. In Europe, tests are systematically carried out by Euro-NCAP, i.e. the European New Car Assessment Program [8-9, 11]. The following programs carry out similar activities, independently of the EuroNCAP: Global NCAP, Japan NCAP, Korean NCAP, Latin NCAP, ASEAN NCAP, IIHS, NHTSA in the USA, NASVA in Japan and ANCAP in Australia. Ratings issued after the crash tests help consumers to choose the safest vehicles. In addition, they motivate the car manufacturers to improve vehicle design and increase driver and passenger safety. The increase in safety systems in motor vehicles is conducive to the decreasing number of road accidents $[4,9,12]$. 
Over the past ten years, there has been a downward trend in frontal and side collisions in Poland, while rear collisions remain at the same level (Figure 1). The comparison of the number of injured in road accidents looks similar in Poland per year, there are 6,000 injured as a result of a rear collision (Figure 2). The number of fatalities in the road accidents has a visible downward trend for fatalities in the side and frontal collisions. Fatalities during the rear impact have remained at the same level for 10 years (Figure 3 ). The rear collisions are becoming more common. This is due to the development of infrastructure. It means that the increase in highways

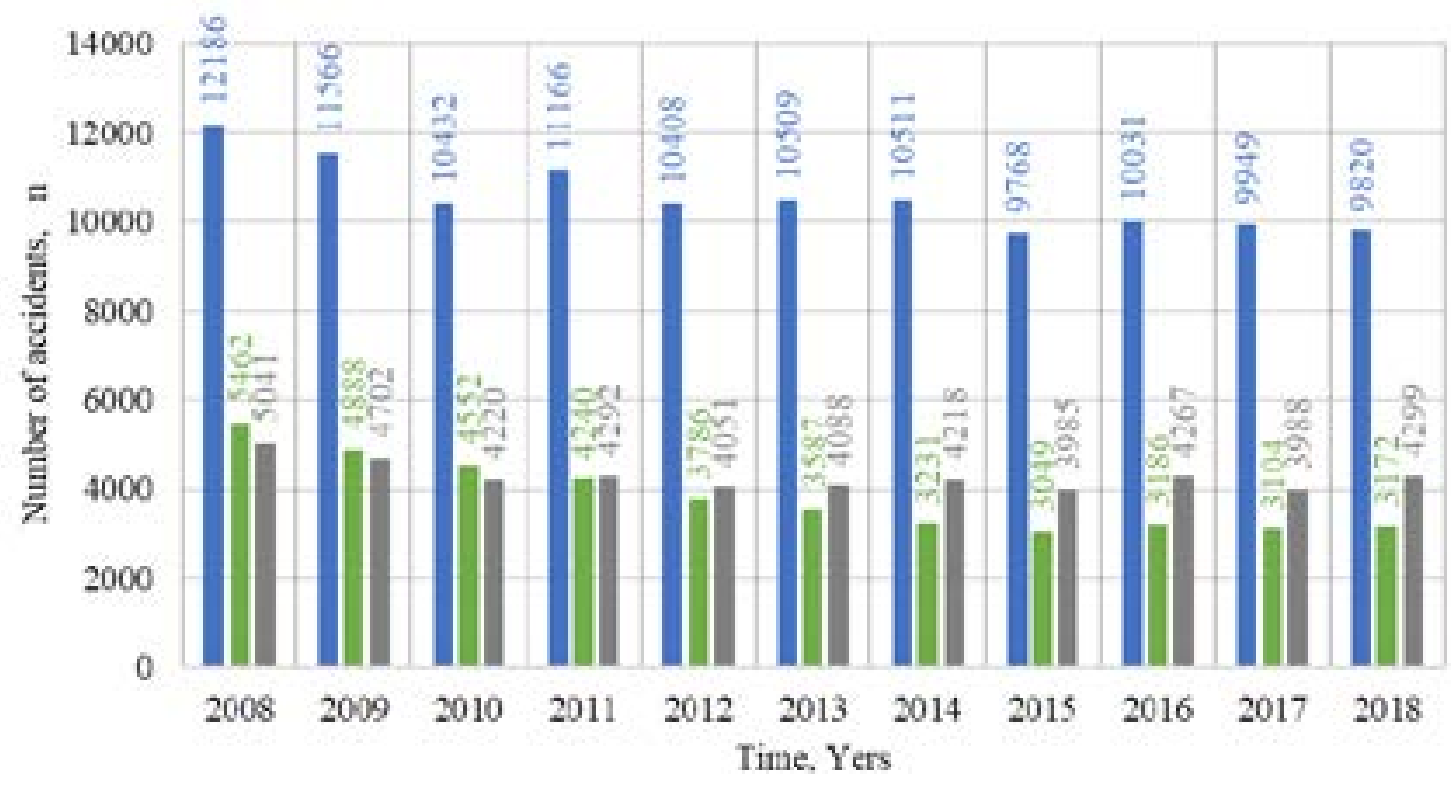

= Side collisions

w Frontal collisions

=Rear collision

Figure 1 Comparison of the number of car accidents in Poland in the years 2008 -2018 [13]

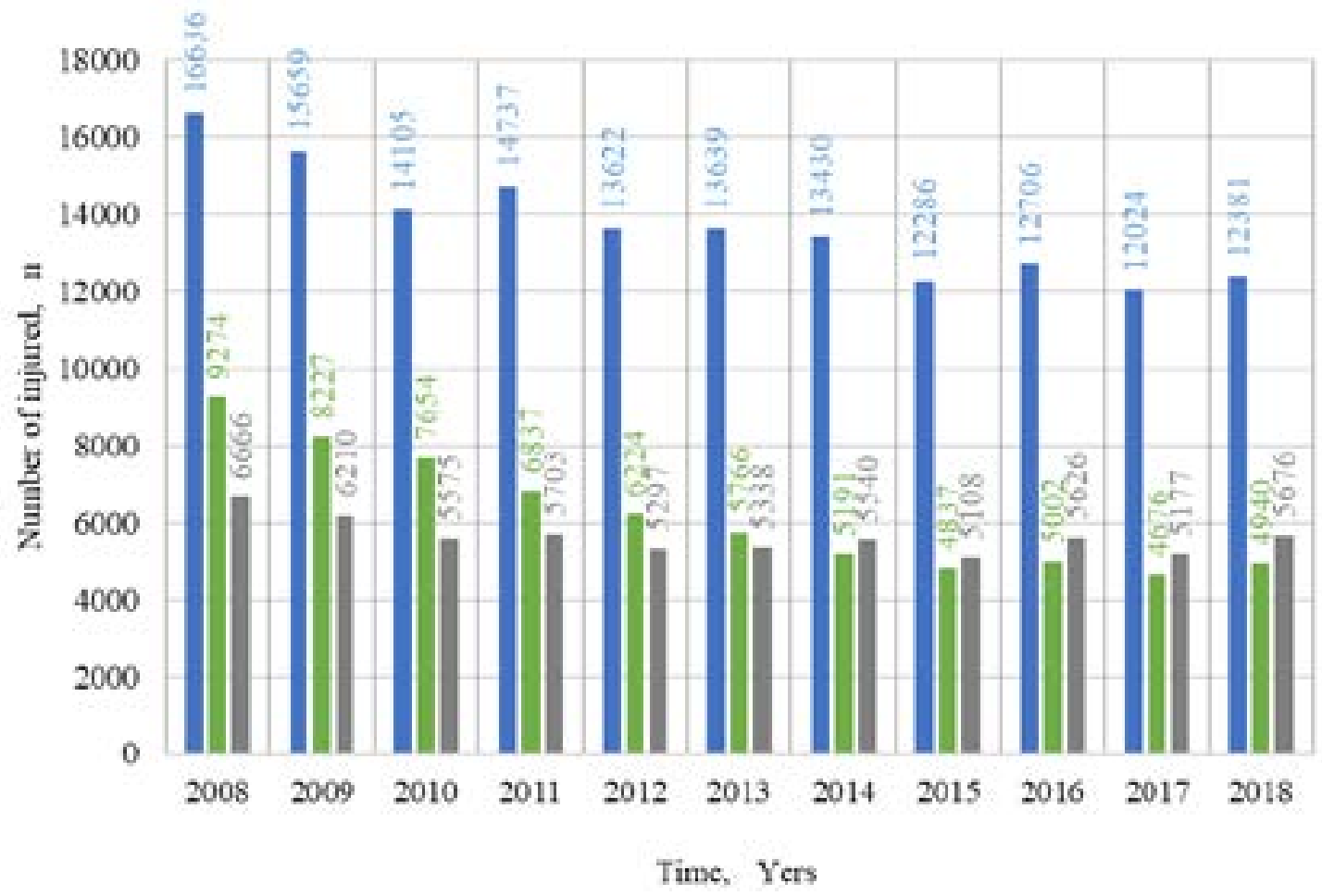

I Side collisions

Erontal collisions

Eear collision

Figure 2 Number of injured in car accidents in Poland in the years 2008 -2018 [13] 


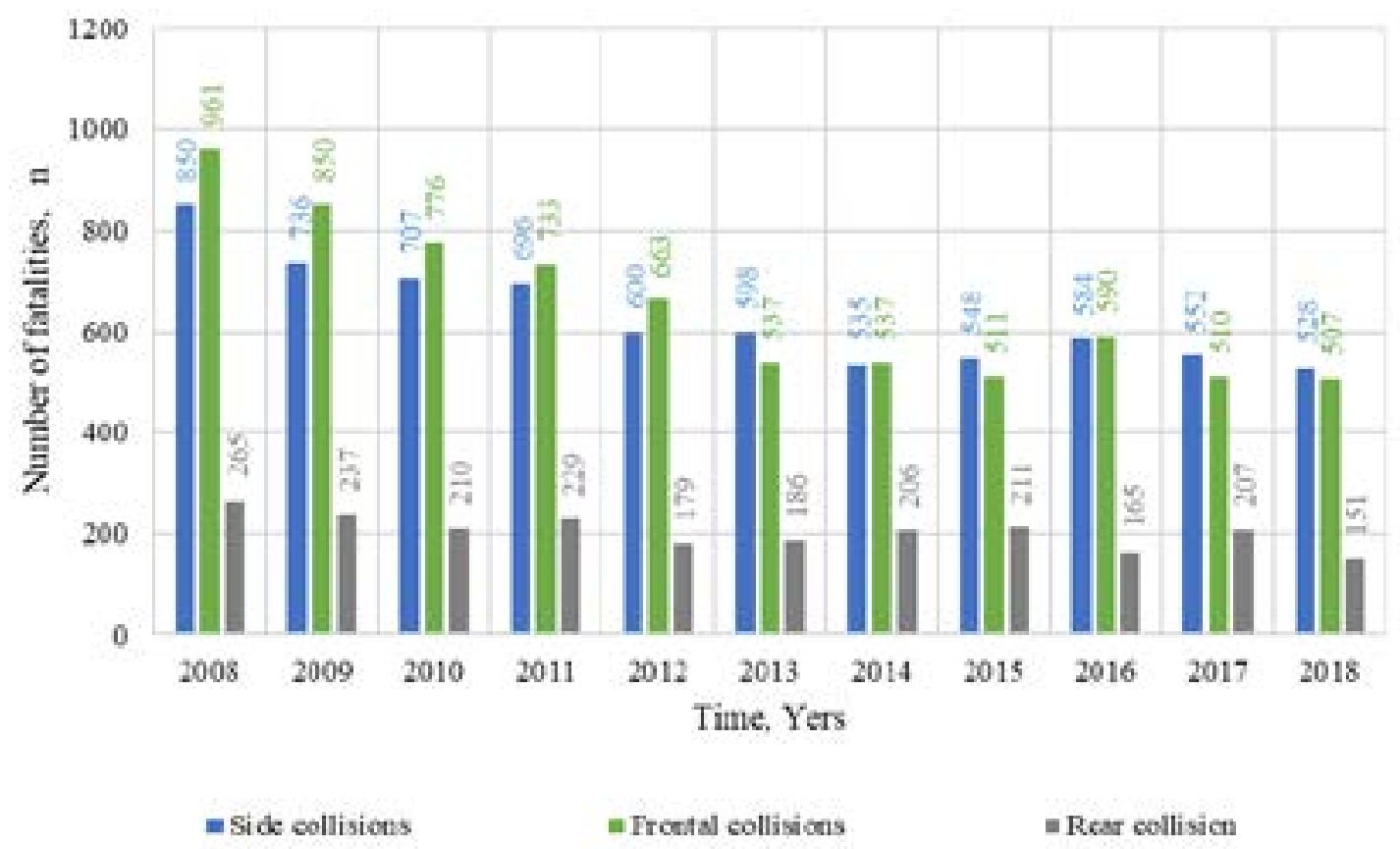

Figure 3 Number of fatalities in car accidents in Poland in the years 2008 -2018 [13]
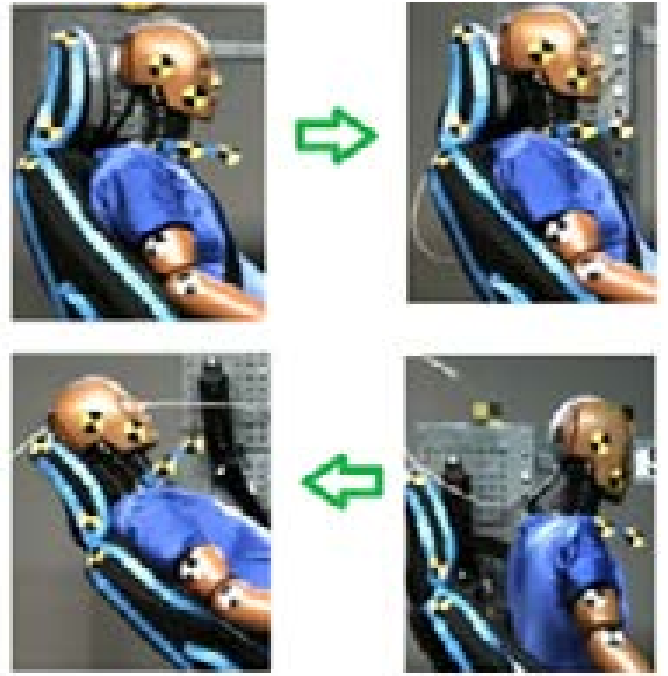

Figure 4 Phases of the head displacement of the rear impact case [18]

and expressways prevents head-on collisions, because the vehicles move in one direction. These conditions favor the occurrence of rear collisions by hitting the rear of the car or not braking the vehicle [10, 13].

The rear collisions occur most often in the speed range from 10 to $30 \mathrm{~km} / \mathrm{h}$. Even at such low speeds, one can experience a serious spinal injury, since during the rear collision, the cervical spine becomes the most vulnerable [7, 11, 16]. The injury may affect muscles, tendons, intervertebral discs and nerves of the head and neck. The spinal injuries can be divided according to the mechanism $[12,16]$ :

- bending- consisting of fracture of the vertebral body and damage to the intercostal and longitudinal posterior ligaments,

- $\quad$ straightened - consisting in damage to the anterior longitudinal ligament and fracture of the first and second cervical vertebra (C1 and $\mathrm{C} 2$ ),

- compression fracture - where the vertebral bodies fracture,

- rotational (rotation of the chin to the shoulder) involving the fracture of the lateral vertebra,

- hyperextension.

Cervical spine injuries associated with rapid and excessive deformity of the spine can be difficult to diagnose and treat for a long time. They are also commonly found in rear impacts at low speed. While such accidents rarely result in fatalities, the consequences of the cervical spine injuries have a huge impact on society, with an estimated annual cost in Europe of around EUR 10 billion [12, 17].

In the event of the rear impact, there are four 


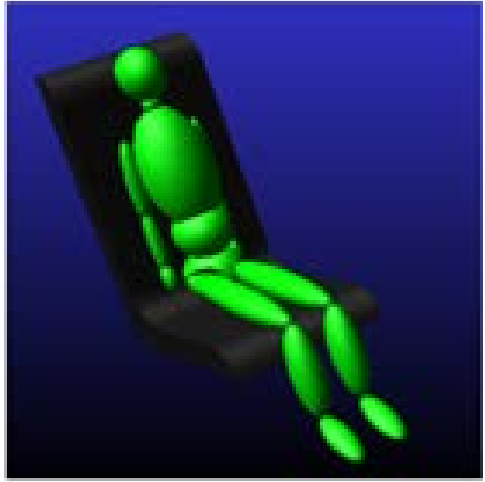

(a)

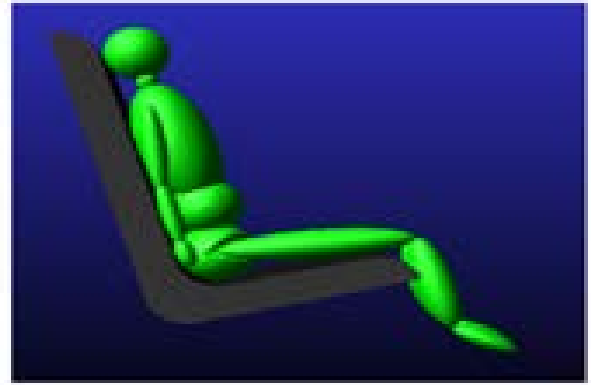

(b)

Figure 5 Anthropometric dummy for the crash tests made in ADAMS program, (a) isometric view, (b) side view

Table 1 The masses of individual body parts of the simulation dummy

\begin{tabular}{ccc}
\hline \multirow{2}{*}{ No. } & \multicolumn{2}{c}{ Simulation dummy } \\
\cline { 2 - 3 } & The name of the block & Mass, $\mathrm{kg}$ \\
\hline 2 & forearm & 3.60 \\
3 & arm & 0.50 \\
4 & hand & 4.60 \\
5 & food & 9.4 \\
6 & shank & 0.60 \\
7 & thigh & 13.80 \\
8 & neck & 0.95 \\
9 & head & 3.70 \\
10 & hips & 20.40 \\
11 & chest & 9.80 \\
() & stomach & 10.00 \\
\hline
\end{tabular}

head displacement stages (Figure 4). In the first phase, the head is moved to the headrest of the chair. Then, in the second phase, the head is pressed against the headrest as a result of the inertial force after the rear impact. In the third phase, the head begins to move forward at a speed increased by the energy of the headrest's elastic force. In the last phase, the head begins to move backwards again relative to the headrest $[12,14,18]$.

Currently, in the frontal impact tests of a car, anthropometric dummies from the Hybryd III family and dummy THOR, representing a 50th percentile man, are used. Anthropometric dummies through the elasticdamping materials used correspond to the structure and behavior of a person during a vehicle collision [14-15].

In the event of rear impacts, the BioRID (50th Male) dummy is used [1, 9-10, 19]. The distinguishing feature of BioRID-II is the spine, which consists of 24 separate vertebrae: 5 lumbar, 12 thoracic and 7 cervical. The other components of the dummy are identical to those of the Hybrid III dummy representing the 50th percentile male. The BioRID dummies only reflect a 50 th percentile male, while there is no crash test dummy representing the female centile population and the 5th and 95th percentile men $[1,20]$.

Crash tests and tests testing various types of security systems require considerable financial and time expenditure. The simulation programs of anthropometric dummies, include such programs as: Madymo, Dytran, Dassault Systemes SIMULIA, ANSYS Engineering Simulation, SIMPACT Caterham Super 7, MSC Software ADAMS. These programs allow to perform simulated crash tests with minimal financial burdens. Only after collecting the appropriate amount of data confirming the effectiveness of simulation tests are the crash tests carried out. The demand for simulation programs and performing computer simulations prior to experimentation affects the development of specialized program networks [18-22].

\section{Research object}

The human model from a physical point is a set of interrelated solids that are characterized by appropriate damping and rigidity. Each block has the right shape 

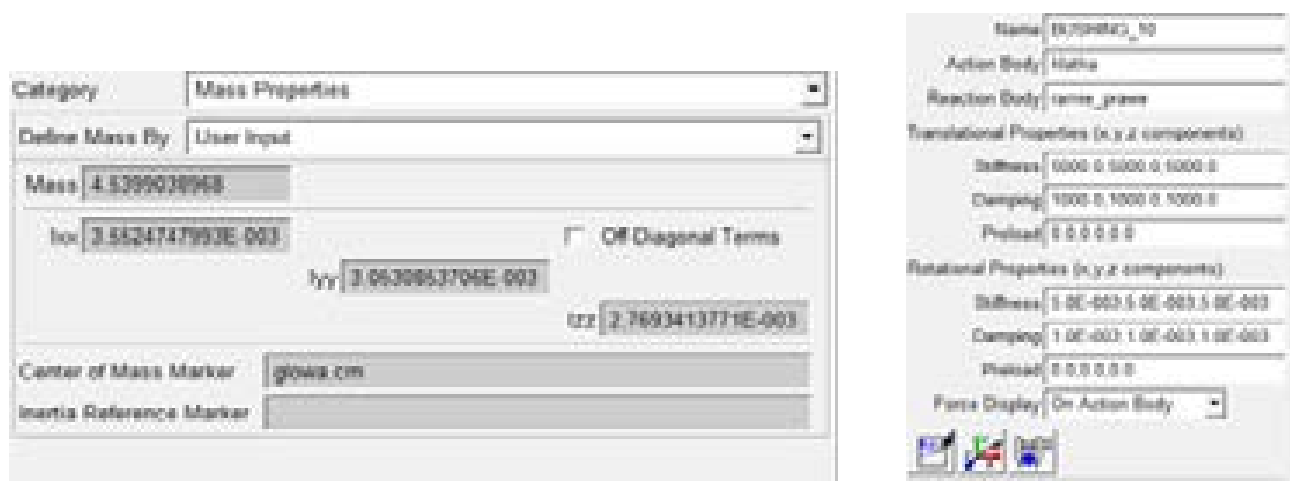

Figure 6 Mass settings and stiffness of elements in ADAMS
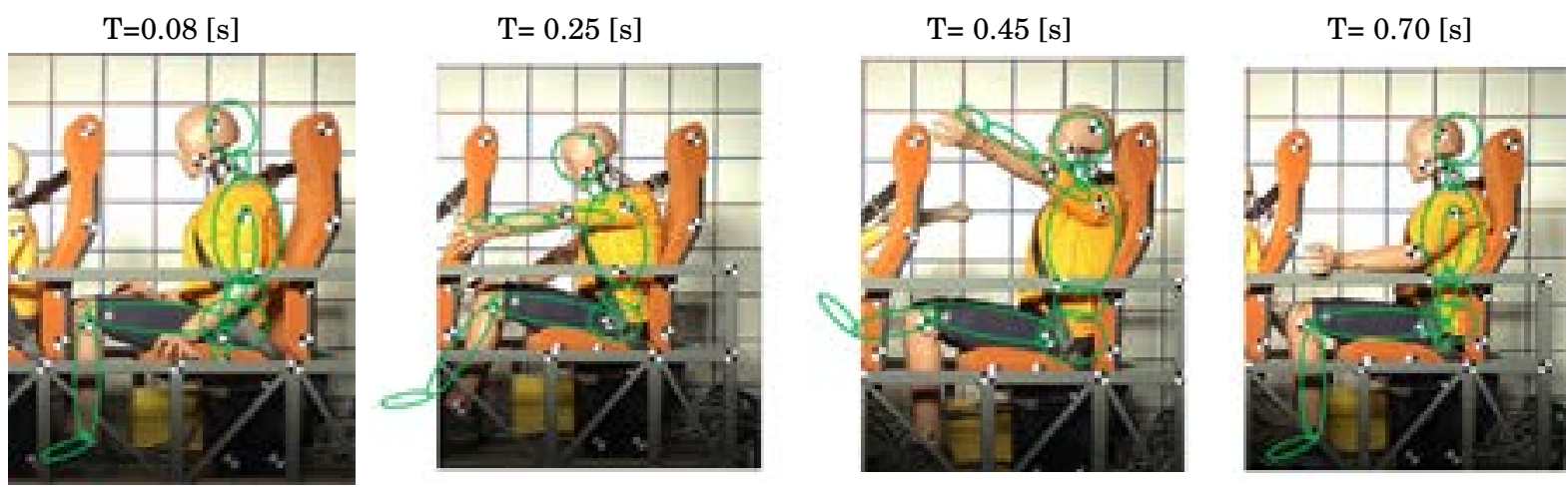

Figure 7 Identification of the basic parameters of the model based on recorded real collisions with dummies

and mass. The designed crash test dummy (Figure 5) at low speed was made in the MSC Adams program. The program can examine the dynamics of movement of individual parts of the dummy's body. It is also possible to determine the distribution of loads and forces acting on individual joints of the dummy. The program enables the transformation of a rigid body into a flexible model for finite element analysis. It allows to modify data and get detailed information about the exact movement of individual parts of the model, presenting them in a graphic way.

The designed dummy model consists of 17 block of a certain mass and size. The dummy was designed in the image of the Hybrid III dummy. Table 1 presents the masses of individual body parts of the designed dummy. The dummy was placed on a car seat consisting of one block, having properly selected stiffness and damping characteristics. The seat belts in the model under construction are a system of parallel springs and vibration dampers mounted in a horizontal plane parallel to the horizontal axis X. The only force on the system is the initial speed.

Creating a model in ADAMS focuses on connecting individual elements with special joints. The program environment makes it easy to make corrections related to mass or stiffness and damping of individual parts. In addition, ADAMS allows to introduce restrictions related to the displacement of individual elements, choose the appropriate articulation and the number of degrees of freedom. Figure 6 presents categories of mass modification and stiffness of elements in ADAMS.

\section{Results of simulation tests}

The simulation dummy was compared with the hybrid III dummy. The experiment was carried out at a speed of $20 \mathrm{~km} / \mathrm{h}$. In order to verify and validate the dummy parameters, the computer simulation crash test was compared to the experimental crash test. An experimental crash test was carried out at a speed of $20 \mathrm{~km} / \mathrm{h}$, using the Hybryd III dummy. The crash test stand is located at the Automotive Industry Institute in Warsaw. The stand for experimental research consists of a trolley to which a car seat with a dummy is attached.

The test element is accelerated by means of the rubber ropes of a total length of 25 meters, five on each side.

The desired speed is obtained by pulling the ropes with the trolley to a certain length. After stretching the trolley ropes for a certain length, the stretched ropes are released and the trolley then gains speed. The desired speed of the trolley is measured in the non-driven section where the trolley moves inertly. Then the trolley is braked with $600 \mathrm{~mm}$ polyurethane bushes. The test run of the experimental event test, carried out at the Automotive Industry Institute in Warsaw, was recorded with a high speed NAC camera at 2500 frames/second [17].

The terms of the trial event experimental test have been reproduced in the MSC Adams program. In the computer simulation, a built-in software camera using 2500 frames per second was used. The simulation time was $5 \mathrm{~s}$. The car seat and the dummy were accelerated 


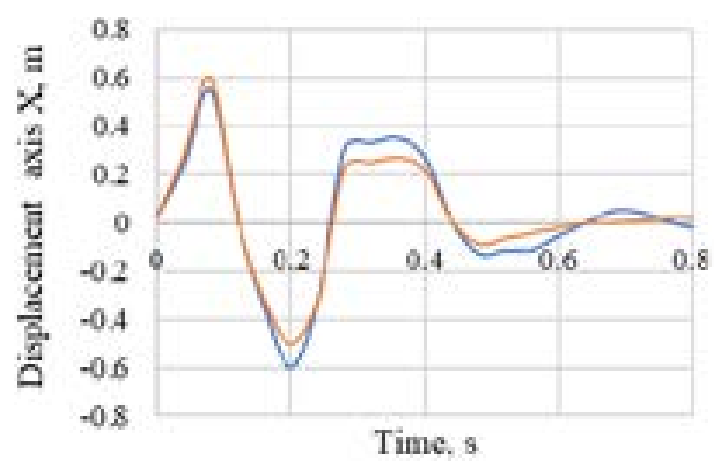

- Experiment - Simulation

(a)

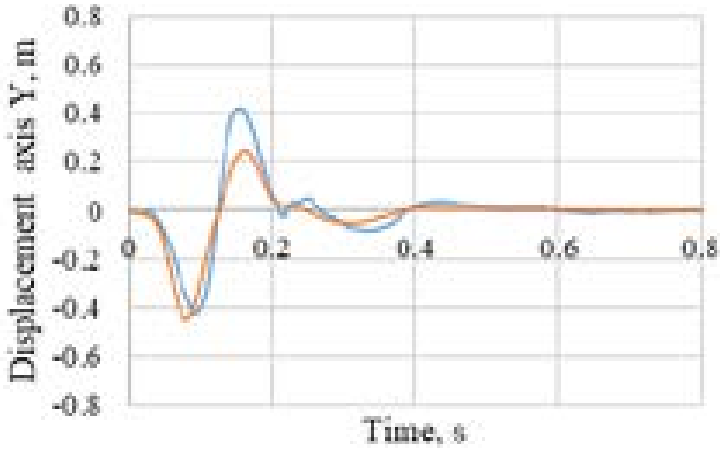

- Experiment - Simulation

(b)

Figure 8 Displacement of the dummy head (a) relative to the $X$ axis, (b) relative to the $Y$ axis

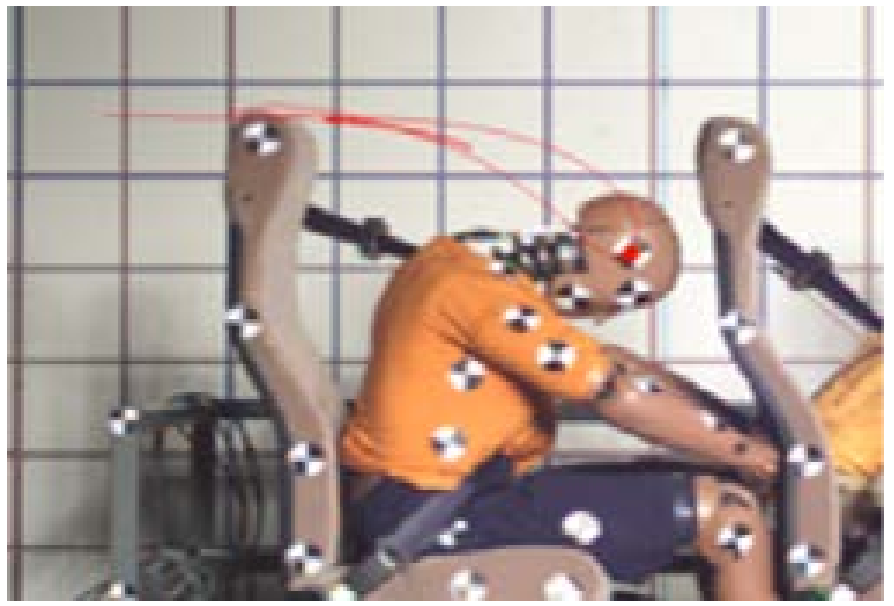

Figure 9 Hybrid III dummy head trajectory during the experiment

from zero to the assumed speed. At this stage, the car seat moved for 2 seconds, after which it was braked to zero. The braking of the car seat is designed to simulate the collision of a vehicle with a stationary obstacle. Computer simulation of the crash test was superimposed to the recorded image of the Hybrid III dummy experimental crash test. Comparison of the simulation to the crash test is shown in Figure 7.

Most often, during the collisions at a low speed, the trauma occurs to the cervical spine - 33\%, head including wounds and concussion $-23 \%$, lower limbs $21 \%$, chest $-8 \%$, other organs $-15 \%$. The most liable parts of the body to damage at low speeds are the neck and head. Figure 8 compares the displacement of the simulation dummy head and the Hybrid III dummy [10, 20-21].

The head displacements in both the $\mathrm{X}$ and $\mathrm{Y}$ axes can be divided into two stages, in the first of them the head moves forward due to the inertia force associated with the rapid braking. Then the head moves towards the headrest of the car seat, hitting it. The second stage of displacement begins when the head hits the car seat headrest, then the head together with the additional force coming from the elasticity of the car seat headrest begins to move forward again.

In the first phase of the head movement, the computer simulation of the crash test obtained the compliance of the movement with the experiment at the level of $95 \%$, while the second phase of the movement achieved the compliance of about $80 \%$. The second phase is closely related to the stiffness and damping of the car seat.

In the TEMA Automotive program, the trajectory of the head of the Hybrid III dummy was determined during the experiment (Figure 9). The superimposed trajectories of the first phase of the head movement of the Hybrid III dummy during the experiment and the anthropometric dummy during the simulation are shown in Figure 10. Considered compatibility of the trajectory of the computer simulation motion with the experiment is at the level of $95 \%$.

In addition, for the purposes of further verification of the compatibility of the computer simulation (the built-in dummy) with the experimental (Dummy Hybrid III), the resultant of the dummy head was determined based on the data from the ADAMS program environment. The resultant head of the simulated dummy was compared to result of the Hybrid III dummy head (Figure 11). 


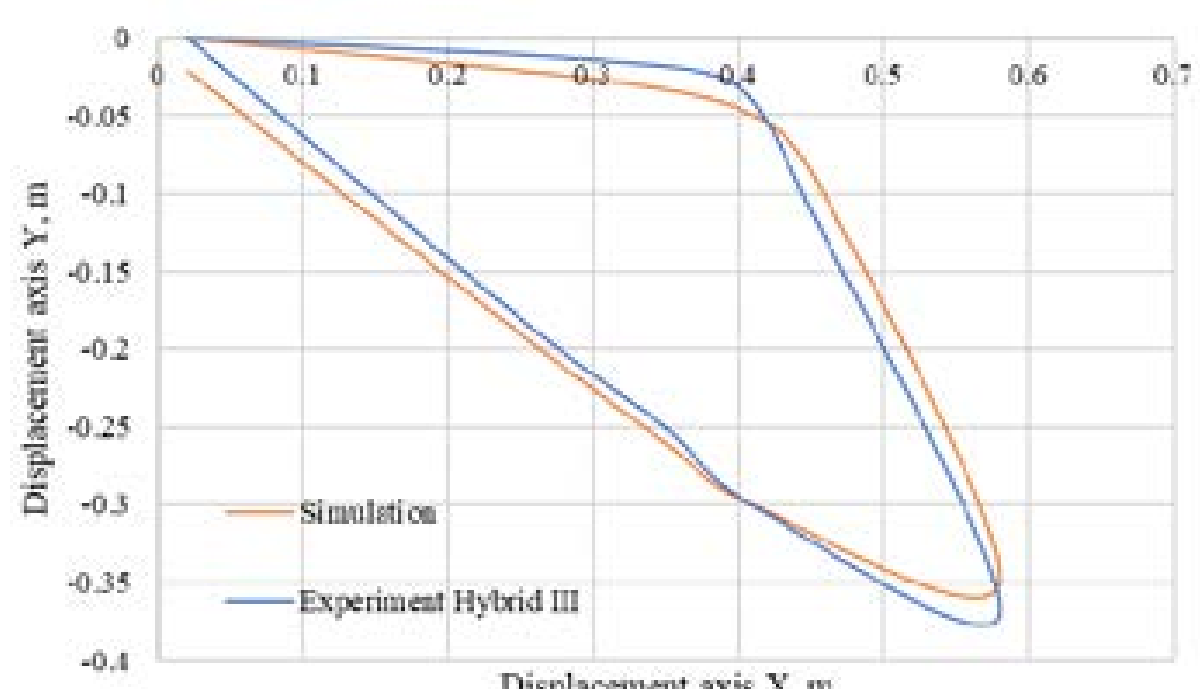

Displacement axis $\mathrm{X}, \mathrm{m}$

Figure 10 Comparison of trajectories of dummies head

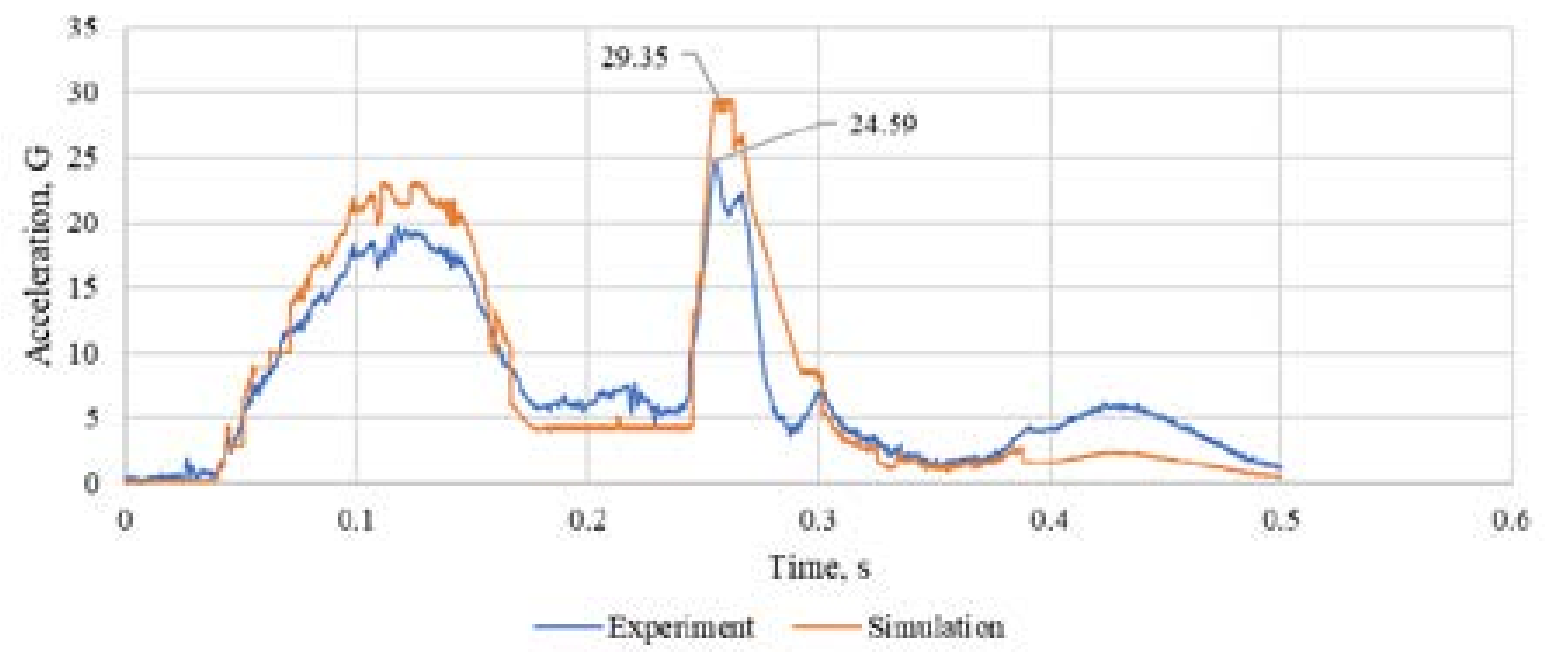

Figure 11 Accidental displacement characteristics of the simulated and experimental dummy head

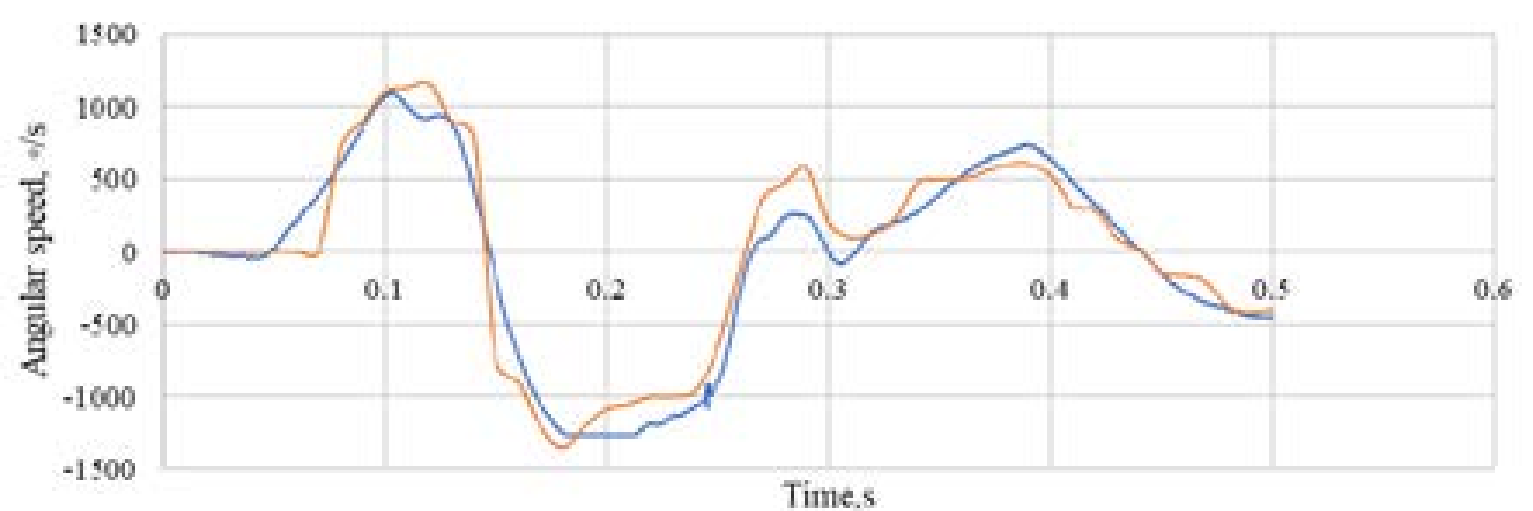

- Experiment Simulation

Figure 12 Angle speed characteristics of the simulated and experimental dummy head 
The difference between the results was up to $19 \%$. On the other hand, Figure 12 shows the angular velocity of the head of the dummies. It can be noticed that the difference between values of the angular velocity of the simulated dummy and the dummy hybrid III overlap in $80 \%$.

\section{Conclusions}

Car accidents in Poland from 2008 to 2018 have a downward trend in the case of frontal and side collisions, whereas rear collisions are maintained at the same level and reach an average of 4,000 per year. The neck spine is the most liable during the rear collision and symptoms often appear several hours after the accident. Only one BioRid II dummy is used for the rear impacts, which is an improved version of the BioRid I from 1989. It represents a 50 percentile man. In the case of the rear collisions, there are no dummies representing the percentile population of women, children and the 5 th and 95th percentile men.

The Adams program allows modifications of the dummy's structure and adopted model parameters. The built in dummy in the program had stiffness and attenuation parameters in accordance with the Hybrid III dummy parameters. Comparison of computer simulation to the experiment at $20 \mathrm{~km} / \mathrm{h}$ showed that the data from the computer simulation differ from the experiment data by $20 \%$. By modifying the parameters of stiffness and damping, as well as the mass of individual parts of the dummy's body, data corresponding to the crash test can be obtained, taking into account individual percentiles of the human population.

It should be emphasized that simulation programs significantly facilitate a number of operations related to improving the safety of motor vehicles. More than 70 years have passed since the creation of the first dummy (Sierra Sam Dummy). There is still a need to design new joints and the construction of individual body parts of the anthropometric dummy to be similar to the human body. Contemporary simulation programs, such as Dytran or ADAMS, are geared towards the crash test simulations and data validation with experimental tests. This is due to the fact that nowadays they are an irreplaceable element of the structure, which must first successfully pass the simulation tests to be able to be physically performed.

Work on the physical structure of a simulation dummy involves use of elements corresponding to the shape, mass and dimensions of individual parts of the human body and also involves use of the special joints reflecting the range of motion of individual human joints.

\section{References}

[1] JASKIEWICZ, M., JURECKI, R., WITASZEK, K., WIECKOWSKI, D. Overview and analysis of dummies used for crash tests. Scientific Journals Maritime University of Szczecin. 2013, 35(107), p. 22-31. ISSN 1733-8670.

[2] LUO, X., DU, W., ZHANG, J. Safety benefits of belt pre-tensioning in conjunction with precrash braking in a frontal crash. In: 2015 IEEE Intelligent Vehicles Symposium (IV): proceedings [online]. IEEE. 2015. ISSN 1931-0587, p. 871-876. Available from: https://doi.org/10.1109/IVS.2015.7225794

[3] FREJ, D., GRABSKI, P. The impact of the unbalanced rear wheel on the vibrating comfort of the child seat. Transportation Research Procedia [online]. 2019, 40, p. 678-685. ISSN 2352-1465. Available from: https://doi. org/10.1016/j.trpro.2019.07.096

[4] GUPTE, S., MASOUD, O., MARTIN, R. F. K., PAPANIKOLOPOULOS, N. P. Detection and classification of vehicles. IEEE Transactions on Intelligent Transportation Systems [online]. 2002, 3(1), p. 37-47. ISSN 15249050, eISSN 1558-0016. Available from: https://doi.org/10.1109/6979.994794

[5] CHEN, Z., ELLIS, T. Multi-shape descriptor vehicle classification for urban traffic. In: 2011 International Conference on Digital Image Computing: Techniques and Applications: proceedings [online]. IEEE. 2011. p. 456461. Available from: https://doi.org/10.1109/DICTA.2011.83

[6] European classification for vehicle category, based in UNECE standards - European Alternative Fuels Observatory [online] [accessed 2020-10-15]. Available from: https://www.eafo.eu/knowledge-center/europeanvehicle-categories

[7] BURCZEWSKI, P., JACKOWSKI, J. Modelling the human body in low speed collisions. Logistyka. 2014, 3, p. 915921. ISSN 1231-5478.

[8] LIU, W., WEN, X., DUAN, B., YUAN, H., WANG, N. Rear vehicle detection and tracking for lane change assist. In: 2007 IEEE Intelligent Vehicles Symposium: proceedings [online]. IEEE. 2007. ISSN 1931-0587, p. 252-257. Available from: https://doi.org/10.1109/IVS.2007.4290123

[9] KIM, S. Y., OH, S.-Y., KANG, J. K., RYU, Y. W., KIM, K., PARK, S.-CH., PARK, K. H. Front and rear vehicle detection and tracking in the day and night times using vision and sonar sensor fusion. In: 2005 IEEE/RSJ International Conference on Intelligent Robots and Systems: proceedings [online]. IEEE. 2005. ISBN 0-78038912-3, p. 2173-2178. Available from: https://doi.org/10.1109/IROS.2005.1545321 
[10] STANCZYK, T. L., ZUSKA, A. Review of anthropo-dynamic dummies used to evaluate the effect of vibrations on sitting human (vehicle driver). The Archives of Automotive Engineering - Archiwum Motoryzacji. 2014, 65(3), p. 65-74. eISSN 2084-476X.

[11] FOSTER, J., KORTGE, J., WOLANIN, M. Hybrid III-A biomechanically-based crash test dummy. SAE Technical Paper [online]. 1977, 770938. ISSN 0148-7191, e-ISSN 2688-3627. Available from: https://doi.org/10.4271/770938

[12] SPITZER, W. O., SKOVRON, M. L., SALMI, L. R., CASSIDY, J. D., DURANCEAU, J., SUISSA, S., ZEISS, E. Scientific monograph of the Quebec Task Force on Whiplash-Associated Disorders: redefining "whiplash" and its management. Spine. 1995, 20(8 Suppl), p. 1S-73S. ISSN 0362-2436, eISSN 1528-1159.

[13] Wypadki drogowe - raporty roczne - Policja (Road accidents - annual reports - Police) [online] [accessed 202004-01]. Available from: http://statystyka.policja.pl/st/ruch-drogowy/76562,Wypadki-drogowe-raporty-roczne.html

[14] ONO, K., KANECKA, K., WITTEK, A., KAJZER, J. Cervical injury mechanism based on the analysis of human cervical vertebral motion and head-neck-torso kinematics during low speed rear impacts. SAE Transactions [online]. 1997, 106(6), p. 3859-3876. ISSN 0096-736X. Available from: www.jstor.org/stable/44720153

[15] HAN, Y., TANG, H., TIAN, F., HUANG, H., MIZUNO, K. Analysis of the equation of motion on the chest of hybrid III 3 YO dummy in dynamic loads. In: 2018 International Conference on Robots \& Intelligent System (ICRIS): proceedings [online]. IEEE. 2018. p. 529-533, Available from: https://doi.org/10.1109/ICRIS.2018.00137

[16] PEARSON, A. M., IVANCIC, P. C., ITO, S., PANJABI, M. M. Facet joint kinematics and injury mechanisms during simulated whiplash. Spine [online]. 2004, 29(4), p. 390-397. ISSN 0362-2436, eISSN 1528-1159. Available from: https://doi.org/10.1097/01.brs.0000090836.50508.f7

[17] Impact of pain on society costs the EU up to 441 billion euros annually - SIP Platform[online] [accessed 2020-1015]. Available from: https://www.sip-platform.eu/press-area/article/impact-of-pain-on-society-costs-the-eu-up-to441-billion-euros-annually

[18] Driving advice - The Automobile Association [online] [accessed 2020-10-15]. Available from: http://www.theaa. com/motoring_advice/safety/whiplash.html

[19] NOUREDDINE, A., ESKANDARIAN, A., DIGGES, K. Computer modelling and validation of a hybrid III dummy for crashworthiness simulation. Mathematical and Computer Modeling. 2002, 35, p. 885-893. ISSN 0895-7177

[20] Humanetics [online] [accessed 2020-10-18]. Available from: https://www.humaneticsatd.com

[21] XU, T., SHENG, X., ZHANG, T., LIU, H., LIANG, X., DING, A. Development and validation of dummies and human models used in crash test. Applied Bionics and Biomechanics [online]. 2018, 2018, 3832850. ISSN 11762322, eISSN 1754-2103. Available from: https://doi.org/10.1155/2018/3832850

[22] JASKIEWICZ, M. Simulation tests of active headrest / Symulacyjne badania dzialania zaglowka aktywnego (in Polish). Doctoral dissertation. Kielce: Politechnika Swietokrzyska, 2007. 